\title{
Modern neuropsychiatric presentation of neurosyphilis
}

\author{
Lindsey Lair, MD; and Andrew M. Naidech, MD, MSPH
}

A s a cause of neuropsychiatric disease, non-HIV related neurosyphilis became uncommon enough for the American Academy of Neurology to drop lumbar puncture from its suggested list of tests for dementia. We reviewed 17 inpatient charts with Centers for Disease Control (CDC) guidelines with definite or probable neurosyphilis. Sixteen presented with neuropsychiatric symptoms, four with overt psychosis. An intensive workup, including lumbar puncture, should be considered in middle-aged patients with new onset neuropsychiatric symptoms.

Syphilis, "the great imitator," used to be part of the standard differential diagnosis of neuropsychiatric disease. With the advent of modern treatment, the incidence of tertiary syphilis has greatly declined. The disease is now considered unusual, except in the context of HIV infection. After anecdotally noting a number of cases, we wished to quantify the number and presentation of cases at our institution.

\section{Methods}

We requested charts of all patients with discharge diagnosis International Classification of Disease-9 (ICD-9) 94.9 from August 1998 to Oc- tober 2001. The charts were systematically screened for CDC criteria for definite (positive CSF VDRL) or probable (elevated CSF protein or leukocytosis with a history of syphilis exposure and no better explanation) neurosyphilis. Infants and patients with a documented positive HIV serology or an AIDS-defining illness were excluded. L.L. reviewed the charts and abstracted each patient's age, complaints, symptoms, serum serologies, neurologic exam, CSF blood counts and glucose, CSF serologies, and treatment. The protocol was approved by the Institutional Review Boards of the Tulane University Health Sciences Center and the Medical Center of Louisiana.

\section{Results}

There were 89 medical records with an ICD-9 discharge diagnosis of neurosyphilis during the study period. We excluded the following: 31 were HIV-positive or had an AIDS-defining illness, 16 could not be located, nine did not have documented syphilis, eight patients refused lumbar puncture (although they had positive serum serology for syphilis exposure), five patients had normal CSF with syphilis, one had meningitis, and one had a history of neurosyphilis more than 10 years before the index admission. Of the 18 charts remaining, one was a neonate born to an included patient.

\section{Clinical features}

Of the 17 patients reviewed (table), the average age was $49.7 \pm$ 12.0 years. All of the patients except one were African-American. Only one patient had a previous history of neuropsychiatric disease, a 40-year-old patient who presented with a complaint of "memory loss." Four patients were committed to the psychiatry service from the emergency department for violent behavior, a thought disorder, or intoxication. Six patients were disoriented to at least the date, four were unable to remember three words at five minutes, three had a normal neurologic exam, three had dysmetria, two patients experienced a convulsion, and two had a cerebral infarction. Every patient underwent lumbar puncture except one in whom multiple attempts were unsuccessful; she was treated with a diagnosis of neurosyphilis because of clinical findings consistent with tabes dorsalis.

Laboratory abnormalities

There were a wide variety of laboratory abnormalities. Two patients had non-reactive nonspecific serum syphilis serologies (serum rapid plasma reagin

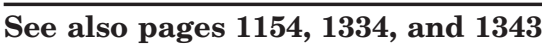

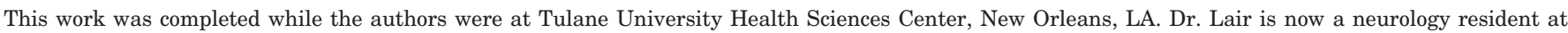
New York University, NY. Dr. Naidech is now at Northwestern University, Davee Department of Neurology, Feinberg School of Medicine, Chicago, IL. Received March 26, 2004. Accepted in final form June 19, 2004.

Address correspondence and reprint requests to Dr. Andrew M. Naidech, 710 N. Lake Shore Dr. \#1422, Chicago, IL 60611; e-mail: a-naidech@northwestern.edu 


\begin{tabular}{|c|c|c|c|c|c|c|}
\hline Age, $y$ & Indication & $\begin{array}{l}\text { Recall of three } \\
\text { objects at } 5 \mathrm{~min}\end{array}$ & Disorientation & $\begin{array}{l}\text { CSF WBC, } \\
\text { cells } / \mathrm{min}^{3}\end{array}$ & $\begin{array}{l}\text { CSF protein, } \\
\mathrm{mg} / \mathrm{dL}\end{array}$ & $\begin{array}{l}\text { CSF } \\
\text { VDRL }\end{array}$ \\
\hline $50 * \dagger$ & Rash, pelvic pain & Normal & No & 0 & 58 & - \\
\hline $56^{*}$ & Disoriented & Normal & Yes & 140 & 657 & + \\
\hline 40 & Memory loss & Normal & No & 40 & 48 & + \\
\hline $51^{*}$ & Disoriented & Decreased & Yes & 132 & 88 & + \\
\hline $44^{*}$ & Bizarre behavior & Normal & No & 61 & 91 & + \\
\hline $40 *$ & Tabes dorsalis & Normal & No & NP & NP & NP \\
\hline $35^{*}$ & Bizarre behavior & Normal & No & 34 & 63 & + \\
\hline 44 & Bizarre behavior & Normal & No & 25 & 80 & + \\
\hline $67^{*}$ & Bizarre behavior & Could not perform & Yes & 0 & 30 & + \\
\hline $78^{*}$ & Seizure & Normal & Yes & 2 & 101 & - \\
\hline $45^{*}$ & Stroke & Normal & Yes & 5 & 37 & + \\
\hline $53^{*}$ & Bizarre behavior & Decreased & Yes & 2 & 78 & + \\
\hline
\end{tabular}

* This patient had a documented positive serum fluorescent treponemal antibody test.

$\uparrow$ This patient gave birth to an infant with neurosyphilis (confirmed by CSF analysis) during the index hospital stay.

$\mathrm{WBC}=$ white blood cells; $\mathrm{NP}=$ not performed.

[RPR] or activated reagin test $[\mathrm{ART}])$, and in three more it was reactive at only two dilutions or fewer. Fourteen of the 17 patients had a serum fluorescent treponemal antibody test (FTA-Abs, a specific test for syphilis exposure in the past) performed; all of these were positive. Our laboratory does not perform FTA-Abs on CSF. Most patients improved after treatment; one patient who declined treatment (after being declared competent to do so) suffered a repeat illness the following year. Other details are shown in the table.

\section{Discussion}

Neurosyphilis was once a relatively common diagnosis in the differential of neuropsychiatric conditions. It was introduced into Europe in the late 15th century, probably by returning explorers from the Americas and the Caribbean, and quickly became an epidemic throughout much of Europe. In the early 20th century a variety of neuropsychiatric conditions were recognized under the general titles of "paretic" or "general paralysis of the insane." Penicillin is highly effective for cure of the infection; before its widespread availability a variety of treatments were peddled including arsenic, mercury and heat therapies. Prior to penicillin potassium, iodide showed documented effectiveness. ${ }^{1}$

Despite the easy availability of penicillin since the 1950 seconds there have been outbreaks of increased incidence of syphilis in the United States, usually every decade or so. The last such outbreak reached its peak in 1990, and since then the rate of new cases has declined. In 2000, the last year for which data are available, the incidence of syphilis of all types continued its downward trend. ${ }^{2}$ Definite neurosyphilis is defined as a positive CSF VDRL test (specific, but only about $50 \%$ sensitive), while probable neurosyphilis means CSF leukocytosis or elevated protein in the context of syphilis exposure without a better explanation. ${ }^{3}$

Seventeen cases over a period of 3 years is comparable to Merritt and Moore's classic study ${ }^{4}$ the Boston City Hospital's 24 confirmed cases over a period of 6 years). Their compilation of 80 cases is the experience of five Boston hospitals over a period of 15 years. However, they commented more upon cranial neuropathies, hydrocephalus, and meningismus. ${ }^{5}$ The largest study of which we are aware ${ }^{6}$ reported on 241 patients diagnosed from 1965 to 1970 . In that series most patients were only mildly symptomatic (peripheral neuropathy was the most common finding) and psychiatric symptoms were uncommon.

Stroke, memory loss, or spinal cord signs are the classic presentations of neurosyphilis, ${ }^{7}$ but these patients presented with short-term memory (STM) loss or dementia, and three were involuntarily committed for bizarre or violent behavior. This is not the first time that a patient with neurosyphilis has been admitted to a psychiatric unit, ${ }^{8}$ but none of the four patients in our series who presented to the hospital for evaluation of a change in behav- 
ior or hallucinations had a history of psychiatric disease. These patients were all older than what would be considered typical for the presentation of a thought disorder.

The serum FTA-Abs test is considered specific and is reported to have a sensitivity of at least $97 \%$ for late syphilis. ${ }^{9}$ When it was performed in these patients it was uniformly positive. A negative FTA-Abs reliably argues against previous exposure to syphilis. The more commonly ordered serum rapid plasmin reagin $(\mathrm{RPR}$, or ART) yielded widely variable results.

The open question is how often we are missing the diagnosis of neurosyphilis entirely. The AAN no longer recommends screening for syphilis as part of a "routine" dementia evaluation; ${ }^{10}$ perhaps a new episode of psychosis in middle age should now be considered an indication for routine screening.
These data have several limitations. Since there is no central database of all patients with syphilis at our institution we were unable to estimate the prevalence of neurosyphilis among all cases. Because of the sensitive nature of the diagnosis, we were allowed to record only prespecified information from the charts of patients in the study. Therefore, a selection bias cannot be ruled out.

In spite of limitations, these data serve to underscore the neuropsychiatric presentation of this infectious disease about 10 years after the last spike in incidence. Behavior change and psychosis in middle age should be added to the classic presentations. A high clinical index of suspicion is mandatory. The most certain way to confirm the diagnosis is with a lumbar puncture, allowing definitive treatment.

\section{References}

1. Dennie CC. A history of syphilis. Springfield, IL: Charles C Thomas, 1962.

2. Centers for Disease Control and Prevention. Summary of notifiable disease-United States, 2000. MMWR Morb Mortal Wkly Rep 2000;49:83.

3. CDC. Case definitions for public health surveillance. MMWR Morb Mortal Wkly Rep 1990;39:1-43.

4. Merritt HH, Moore M. Acute syphilitic meningitis. Medicine 1935;14:119-183.

5. Merritt HH, Adams RD, Solomon HC. Neurosyphilis. New York: Oxford University Press, 1946.

6. Hooshmand H, Escobar MR, Kopf SW. Neurosyphilis: a study of 241 patients. JAMA 1972;219:726-729.

7. Coyle PK. infectious disorders. In: Bogousslavsky J, Fisher M, eds. Textbook of neurology. Boston: Butterworth Heinemann, 1998.

8. Reeves RR, Pendarvis EJ, Kimble R. Unrecognized medical emergencies admitted to psychiatric units. Am J Emerg Med 2000;18: 390-393.

9. Tramont EC. Treponema pallidum (syphilis). In: Mandell, ed. Principals and practice of infectious diseases, 5th ed. Orlando: Churchill Livingstone, 2000.

10. Knopman DS, DeKosky ST, Cummings JL, et al. Practice parameter: diagnosis of dementia (an evidence-based review). Report of the quality standards subcommittee of the American Academy of Neurology. Neurology 2001;56:1143-1153. 


\section{Neurology}

\section{Modern neuropsychiatric presentation of neurosyphilis \\ Lindsey Lair and Andrew M. Naidech}

Neurology 2004;63;1331-1333

DOI 10.1212/01.WNL.0000140254.61842.9C

\section{This information is current as of October 11, 2004}

\section{Updated Information \&} Services

References

Permissions \& Licensing

Reprints including high resolution figures, can be found at: http://n.neurology.org/content/63/7/1331.full

This article cites 4 articles, 1 of which you can access for free at: http://n.neurology.org/content/63/7/1331.full\#ref-list-1

Information about reproducing this article in parts (figures,tables) or in its entirety can be found online at:

http://www.neurology.org/about/about_the_journal\#permissions

Information about ordering reprints can be found online: http://n.neurology.org/subscribers/advertise

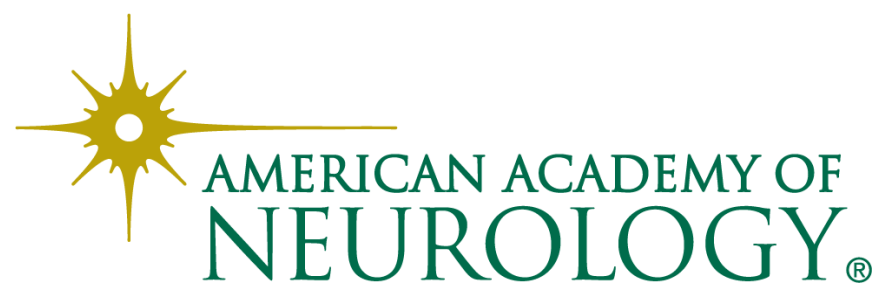

